\title{
Kalsiyumoksit (CaO) ve Magnezyumoksit (MgO) İçeriğine Sahip Termal Bariyer Kaplamaların (TBCs) Mikroyapısal ve Mekaniksel Özelliklerinin İncelenmesi
}

\section{Investigation of Micro-structural and Mechanical Properties of Thermal Barrier Coatings (TBCs) Containing Calcium Oxide ( $\mathrm{CaO}$ ) and Magnesium Oxide (MgO)}

\begin{abstract}
Yasin Özgürlük ${ }^{1 *}$
Geliş / Received: 03/04/2021

Revize / Revised: 07/10/2021

Kabul / Accepted: 08/10/2021

ÖZ

Termal bariyer kaplamalar (TBCs), havacılık endüstrisindeki gaz türbin motorlarının yanma odaları ve türbin kanatçıkları gibi yüksek sıcaklıklara maruz kalan kritik bölge parçalarında 1sıl yalıtım sağlanması amacıyla kullanılan kaplama türüdür. TBC sistemlerin kullanımı ile metalik parçaların yüzey sıcaklığının azaltılarak türbin verimliliğinin artırılması ve daha uzun kullanım ömrü elde edilmesi sağlanmaktadır. Bu çalışmada, Inconel 718 süper alaşım altlık malzeme üzerine CoNiCrAlY içeriğine sahip metalik bağ kaplamalar yaklaşık $100 \mu \mathrm{m}$ kalınlığa sahip olarak atmosferik plazma sprey (APS) kaplama yöntemi kullanılarak üretilmiştir. TBC sistemlerinin $\mathrm{CaO}$ ile stabilize edilmiş zirkonya (CSZ) ve $\mathrm{MgO}$ ile stabilize zirkonya (MSZ) üst seramik kaplamaları yaklaşık $300 \mu \mathrm{m}$ kalınlığa sahip olarak APS yöntemi kullanılarak üretilmiştir. Üretilen farklı TBC sistemlerinin üretim sonrası mikroyapısal ve mekanik özellikleri karşılaştırmalı olarak incelenerek, değerlendirilmiştir. Kaplamaların mikroyapısal özellikleri ve faz yapıları taramalı elektron mikroskobu (SEM), elemental haritalama ve X-Işını Difraktometresi (XRD) analizleri kullanılarak belirlenmiştir. Ayrıca, mikroyapı ve faz yapıları haricinde porozite, sertlik ve yüzey pürüzlülük özellikleri ölçülerek sunulmuştur. Elde edilen analiz sonuçları, bulgular ve TBC sistemleri literatürdeki diğer ilgili çalışmalar ışığında karşılaştırmalı olarak değerlendirilmiştir.
\end{abstract}

Anahtar Kelimeler- Termal Bariyer Kaplamalar (TBCs), Atmosferik Plazma Sprey (APS),Magnezyumoksit (MgO), Kalsiyumoksit (CaO)

\begin{abstract}
Thermal barrier coatings (TBCs) are a type of coating used to provide thermal insulation in critical zone parts exposed to high temperatures, such as combustion chambers and turbine blades of gas turbine engines in the aviation industry. With the use of TBC systems, it is ensured that the surface temperature of metallic parts is increased and the efficiency of the turbine is increased, and the longer service life is achieved. The metallic material used as a substrate for a typical TBC system has a combination of metallic bond coating with MCrAlY content and yttria-stabilized zirconia coating (YSZ). In this study, metallic bond coatings with CoNiCrAlY content on Inconel 718 superalloy substrate were produced using atmospheric plasma spray (APS) coating method with a thickness of approximately $100 \mu \mathrm{m}$. CaO stabilized zirconia (CSZ) and MgO stabilized zirconia (MSZ) top ceramic coatings of TBC systems were produced using the APS method with a thickness of approximately 300
\end{abstract}

1*Sorumlu yazar iletişim: yozgurluk@bartin.edu.tr (https://orcid.org/0000-0003-1121-5018)

Metalurji ve Malzeme Mühendisliği Bölümü, Bartın Üniversitesi, Mühendislik, Mimarlık ve Tasarım Fakültesi, Bartın, Türkiye 
$\mu \mathrm{m}$. Post-production microstructural and mechanical properties of different TBC systems produced were comparatively investigated and evaluated. Microstructural properties, and phase structures of the coatings were determined using scanning electron microscopy (SEM), elemental mapping, and X-Ray Diffractometry (XRD) analysis. Also, apart from microstructure and phase structures, porosity, hardness, and surface roughness properties were measured. The obtained analysis results, findings, and TBC systems were evaluated comparatively in the light of other relevant studies in the literature.

Keywords- Thermal Barrier Coatings (TBCs), Atmospheric Plasma Spray (APS), Magnesium Oxide (MgO), Calcium Oxide ( $\mathrm{CaO})$

\section{GIIRIŞ}

TBC sistemleri hem endüstriyel gaz türbinlerinde hem de uçak motorlarında yaygın olarak kullanılmaktadır. Bu sistemler, yüksek sıcaklık uygulamalarında 1Sı yalıtımı sağlarken, kullanım koşullarında sıcaklık düşüşü sağlar. Ayrıca bu sistemler, yanma türbinlerinin yapısal yüklerini aşırı ortamlardan (yüksek sıcaklık, yüksek basınç, korozyon) koruyan ve gaz türbinli motorların daha iyi verimliliği ve performansı için tercih edilen malzeme sistemleridir [1]. Bilim adamları ve yüzey mühendisleri TBC' leri geliştirmek için birçok çalışmalar yapmaktadır ve TBC teknolojilerinin gaz türbini endüstrisinin satış ve onarım işi üzerinde önemli bir etkiye sahip olduğu göz önüne alındığında, türbin parçaları Ar-Ge çalışmalarının ana odağı haline gelmiştir. Geleneksel bir TBC sistemi 4 farklı katmandan oluşur. Bu katmanlar seramik üst kaplama, termal olarak büyüyen oksit tabakası (TGO), bağ kaplama ve altlık malzemedir. Yoğun olarak çalışan dizel motorları ve gaz türbinleri gibi yüksek sıcaklık uygulamalarındaki yüksek performansı nedeniyle kullanılan üst kaplama malzemelerinden biri, zirkonyadır $\left(\mathrm{ZrO}_{2}\right)$ [2-4]. Saf $\mathrm{ZrO}_{2}$, dikkate alınması gereken iki fazlı dönüşümlere sahiptir. Tetragonal fazdan monoklinik faza dönüşüm $\mathrm{ZrO}_{2}$ yapısında \%3-5 hacim değişimine neden olur. $\mathrm{Bu}$ hacim değişimi de $\mathrm{ZrO}_{2}$ yapısının hasara uğramasına sebep olur. $\mathrm{ZrO}_{2}{ }^{\prime}$ ye $\mathrm{CaO}, \mathrm{MgO}, \mathrm{Y}_{2} \mathrm{O}_{3}$ ve $\mathrm{CeO}_{2}$ gibi bileşiklerin eklenmesiyle tetragonal yapı, faz değişikliği olmaksızın tüm sıcaklıklarda stabil hale gelir; bu durum stabilize $\mathrm{ZrO}_{2}$ olarak bilinir [4,5]. Mekanik, termal, indirgeyici ve korozif ortam ile ilgili çalışma koşullarında yer alan zorluklar nedeniyle, termal bariyer kaplamalar yüksek erime noktası, oda sıcaklığı ile çalışma sıcaklığı arasında faz dönüşümü olmaması, düşük iletkenlik, kimyasal olarak inert gibi özelliklere sahip olmalıdır. Ayrıca metalik bağ kaplama ve üst kaplama arasındaki termal genleşme katsayısının uygun bir koordinasyon içinde olması gereklidir [4,6]. Günümüze kadar gerçekleştirilen çalışmalarda, termal bariyer kaplama malzemesi olarak birkaç bileşik kullanılmıştır; ancak, termal bariyer kaplama için tüm uygun özelliklere sahip tek bir malzeme henüz önerilmemiştir. Jet motorlarında, çalışan egzoz memesi malzemeleri, 1sı yalıtımı sağlamak için $\mathrm{MgO}+\mathrm{ZrO}_{2}(\mathrm{MSZ})$ ve $\mathrm{CaO}+\mathrm{ZrO}_{2}(\mathrm{CSZ})$ ile kaplanabilir. Her iki TBC sisteminin termal özellikleri ile ilgili olarak, MSZ ve CSZ termal iletkenliği $\mathrm{Y}_{2} \mathrm{O}_{3}+\mathrm{ZrO}_{2}$ (YSZ)' kinden nispeten daha düşüktür. Diğer yandan, MSZ ve CSZ sistemlerinin 1sıl genleşme katsayısı YSZ kaplamaya yakın özellik göstermektedir [7]. Çok yüksek erime noktalarına sahip bu üst kaplama malzemeleri çoğunlukla termal sprey kaplama yöntemlerinden olan APS yöntemiyle üretilmektedir. Üretim yöntemi kaplama kalınlığı, aerodinamik gereksinim, tamir edilebilirlik ve üretim maliyetleri gibi faktörlere bağlıdır [8,9].

Bağ kaplama tabakası, TBC sisteminde TGO oluşumu sırasında $\alpha-\mathrm{Al}_{2} \mathrm{O}_{3}$ oluşumunu kolaylaştırmak için yerel bir Al rezervuarı görevi görür. TBC' deki bağ kaplama tabakası, TGO' nun morfolojisini şekillendirdiği ve dayanıklılığını artırdığı için sistemdeki en önemli bileşendir [10,11].Yaygın olarak kullanılan bă̆ kaplama malzemesi MCrAlY (burada M: Ni veya Co veya her ikisi)'dir. Sistemdeki bağ kaplamanın işlevi, yüksek sıcaklıklarda oluşan oksidasyonu önlerken altlık malzemenin oksidasyon süresini uzatmaktır. Bağ kaplamaların içeriği metal bazlı olduğundan, termal püskürtme yöntemlerinin çoğu ile bunları üretmek mümkündür [12]. Literatürde en çok tercih edilen yöntem ise, uygulamadaki kolaylığı ve uygun maliyetinden dolayı APS yöntemidir. Süper alaşım altlık malzemelerinin özelliği, yüksek sıcaklıklarda uzun süreli sıcak korozyon ve aşınmaya karşı yüksek dirençleridir. TBC sistemleri servis kullanım koşulları altında oksidasyon, korozyon, termal şok ve $\mathrm{CaO}-\mathrm{MgO}-\mathrm{Al}_{2} \mathrm{O}_{3}-\mathrm{SiO}_{2}$ (CMAS) etkisi gibi farklı agresif çevresel koşullarına maruz kalmaktadır. Yüksek sıcaklıklar, atmosferden gelen oksijen, uçaklarda ve jetlerde kullanılan yakıtlardan kaynaklanan $\mathrm{V}_{2} \mathrm{O}_{5}$ ve $\mathrm{Na}_{2} \mathrm{SO}_{4}$ safsızlıkları, volkanik dağ bölgelerinden ve çöl ortamlarından gelen toz partikülleri oksidasyona, sıcak korozyona ve CMAS hasarına neden olmaktadır [13,14]. 
Bu çalışmanın amacı, geleneksel TBC malzemesi olan YSZ'ye alternatif olarak gerçekleștirilen TBC malzemeleri olan CSZ ve MSZ kaplamaların mikroyapısal ve mekaniksel özelliklerinin birbirleri ve literatürdeki çalışmalar esas alınarak karşılaştırmalı olarak incelenmesidir.

\section{MATERYAL VE YÖNTEM}

\section{A. Altlk Malzemenin Karakterizasyonu}

Bu çalışmada, uzay ve havacılık endüstrisinde yaygın bir şekilde kullanılan oksidasyona, sürünmeye ve korozyona karşı direnci yüksek olan nikel esash Inconel 718 süperalaşım malzeme TBC sisteminde altlık malzeme olarak kullanılmıştır. Servis koşulları altında hasar oluşumlarına karşı dayanıklı olan Inconel 718 çökelme sertleştirmesiyle elde edilmiş nikel-krom esaslı bir malzemedir. Alaşım içerisinde molibden, niyobiyum, titanyum ve alüminyum da bulunmaktadır. Tablo 1'de Inconel 718 süper alaşım malzemenin fiziksel özellikleri, Tablo 2'de ise mekanik özellikler ayrıntılı bir şekilde verilmiştir.

Tablo 1. Nikel esaslı süper alaşım Inconel 718 altlık malzemeye ait fiziksel özellikler [15]

\begin{tabular}{c|c} 
Erime Noktası & $1260-1336^{\circ} \mathrm{C}$ \\
Yoğunluk & $8,5 \mathrm{~g} / \mathrm{cm}^{3}$ \\
Isıl İletkenlik & $11,4 \mathrm{~W} / \mathrm{mK}$ \\
Isısal Genleşme Sabiti & $7,2-13,0 \mu \mathrm{m} / \mathrm{m} \cdot \mathrm{K}$ \\
Elektriksel Direnç & $1250 \mathrm{n} . \mathrm{m}$ \\
Özısı & $435-0,104 \mathrm{~J} / \mathrm{kg} . \mathrm{K}$ \\
\hline
\end{tabular}

Tablo 2. Inconel 718 altlık malzemenin mekanik özellikleri [15]

\begin{tabular}{c|c|c|c}
\hline $\begin{array}{c}\text { Test Sıcaklığı } \\
\left({ }^{\circ} \boldsymbol{C}\right)\end{array}$ & $\begin{array}{c}\text { 0.2\% Akma Dayanımı } \\
(\boldsymbol{M P a})\end{array}$ & $\begin{array}{c}\text { Çekme Dayanımı } \\
(\boldsymbol{M P a})\end{array}$ & $\begin{array}{c}\text { Uzama } \\
\%\end{array}$ \\
\hline 93 & 1172 & 1407 & 21 \\
204 & 1124 & 1365 & 20 \\
316 & 1096 & 1344 & 20 \\
427 & 1076 & 1317 & 19 \\
538 & 1069 & 1276 & 18 \\
649 & 1027 & 1158 & 19 \\
760 & 758 & 758 & 27 \\
\hline
\end{tabular}

Inconel 718 malzeme ticari olarak piyasada uzun silindirler şeklinde bulunmaktadır. Deneysel çalışmalarda kullanılan nikel esaslı Inconel 718,1 inç $(25,4 \mathrm{~mm})$ çapında silindirik çubuklar halindetemin edilmiştir. Ticari olarak elde edilen çubuklar yaklaşık 5 mm'lik kalınlıklar halinde tel erozyon kesme prosesi yardımıyla kesilmiştir. Inconel 718 malzemeye ait kimyasal bileşim Tablo 3'te verilmektedir.

Tablo 3. Inconel 718 süperalaşım malzemeye ait kimyasal bileşim [16]

\begin{tabular}{lcccccccc}
\hline & \multicolumn{1}{c}{ Inconel 718 Kimyasal Bileşim (\%ăg.) } & & & Al \\
\hline Element & $\mathbf{N i}$ & $\mathbf{F e}$ & $\mathbf{C r}$ & $\mathbf{N b}$ & $\mathbf{M o}$ & $\mathbf{T i}$ & $\mathbf{C o}$ \\
\cline { 2 - 10 } Ăgrlıkça (\%) & 54,20 & 19,03 & 17,95 & 4,02 & 2,89 & 1 & 0,49 & 0,18 \\
\hline Element & $\mathbf{S i}$ & $\mathbf{C u}$ & $\mathbf{M n}$ & $\mathbf{C}$ & $\mathbf{T a}$ & $\mathbf{B}$ & $\mathbf{S}$ & \\
Ăğırlıkça (\%) & 0,08 & 0,04 & 0,07 & 0,024 & 0,01 & 0,003 & 0,004 & \\
\hline
\end{tabular}

Kesme işleminin ardından Inconel 718 süperalaşım altlık malzemeler metalik bağ kaplama işlemleri için hazır hale getirilmiştir. Bağ kaplama malzemesinin altlık yüzeyine tutunmasının daha iyi olması ve yüzeyinde bulunan oksit ve kir tabakalarının uzaklaştııılması için altlık malzemeler kumlama işlemine tabi tutulmuşlardır. Kumlama işlemi için 55-60 mesh boyut aralığındaki $\mathrm{Al}_{2} \mathrm{O}_{3}$ aşındırıcı parçacıkları kullanılarak yaklaşık $75-90^{\circ}$ 'lik bir açı ve 3 bar'lık basınçlı hava ile püskürtülerek sağlanmıştır. Kumlama işlemi yardımıyla altlık malzeme yüzeyleri pürüzlendirilmiş ve bu sayede bağ kaplama malzemesinin yüzeye daha iyi tutunması sağlanmıştır. Kumlama işleminin ardından altlık malzemeler alkol içerisinde ultrasonik temizleme işlemine tabi tutulmuştur. Temizlenen numunelerin bağ kaplama işlemleri APS yöntemi kullanılarak gerçekleştirilmiştir. Yaklaşık $100 \mu \mathrm{m}$ kalınlığındaki CoNiCrAlY bağ kaplama katmanı Inconel 718 süper alaşım altlık malzemelerin üzerine APS tekniği 


\begin{tabular}{|c|c|c|}
\hline & $\begin{array}{l}\text { BŞEÜ Fen Bilimleri Dergisi } \\
8(2), 604-613,2021\end{array}$ & $\begin{array}{r}\text { BSEU Journal of Science } \\
\text { https://doi.org/10.35193/bseufbd.909078 }\end{array}$ \\
\hline |ER R & & 2458-7575 (https://dergipark.org.tr/tr/pub/bseufbd) \\
\hline
\end{tabular}

kullanılarak kaplanmıştır. Bağ kaplama işleminin ardından MSZ ve CSZ içerikli seramik üst kaplama tozları yine APS yöntemi kullanılarak yaklaşık $300 \mu \mathrm{m}$ kalınlık olacak şekilde kaplanarak TBC üretimleri tamamlanmıştır.

\section{B. Kaplama Tozlarının Mikroyapısal Karakterizasyonu}

MAIA3 TESCAN SEM cihazının kullanıldığı kaplama toz malzemelerinin karakterizasyon işleminde, 2000x büyütmeye kadar çıkılarak görüntüler alınmıştır. Gerçekleştirilen SEM analizi neticesinde tozların farklı geometrik şekillerde ve sık aralıklı olduğu görülmüştür. Şekil 1a'da MSZ kaplama tozuna ait, Şekil 1b' de ise, CSZ kaplama tozuna ait SEM görüntüleri mevcuttur. Her iki mikroyapı görüntülerinden de kaplama tozlarının küresel şekle yakın fakat çoğunlukla köşeli bir yapıya sahip olduğu görülmektedir.
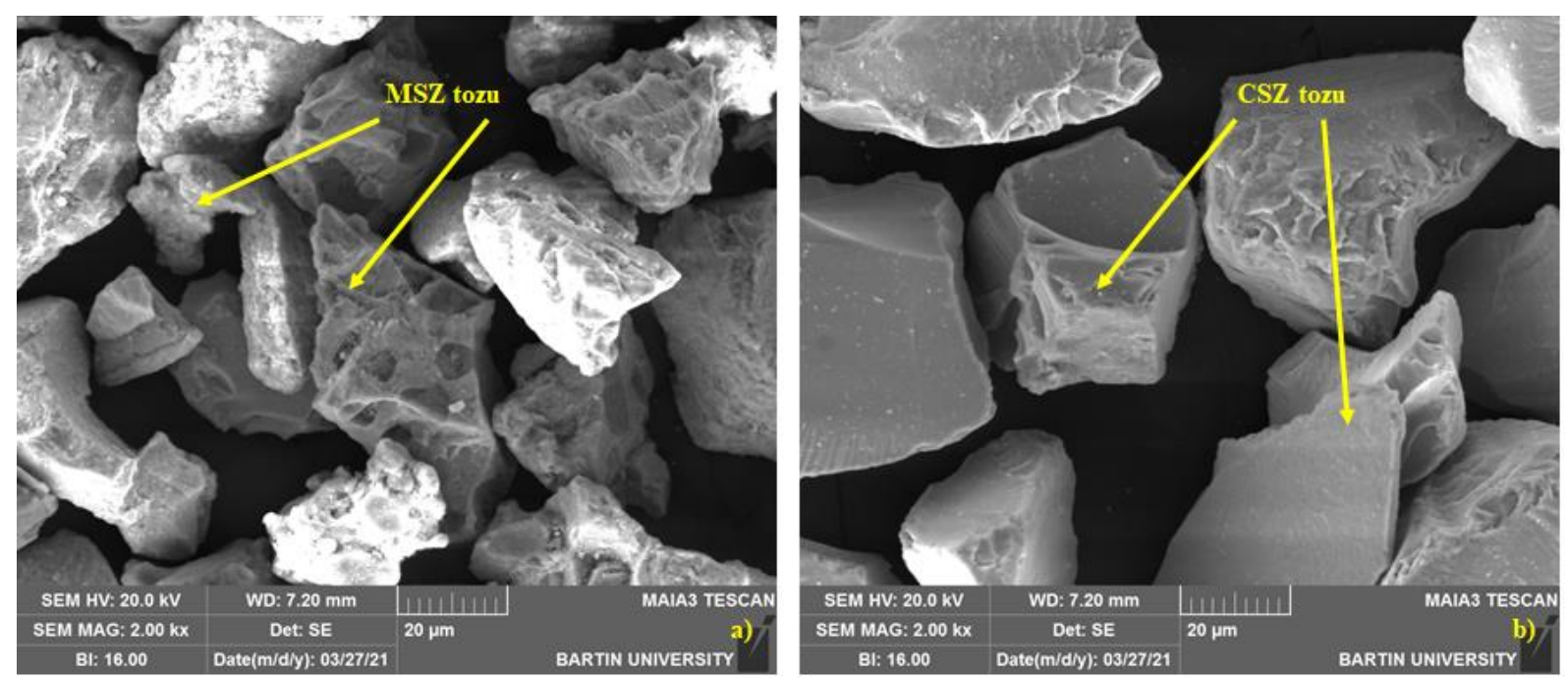

Şekil 1.KaplamaTozlarının Mikroyapısal SEM görüntüsü: a) MSZtozu, b) CSZ tozu

Kaplama tozlarının ortalama hangi boyutlarda olduğunun tespit edilebilmesi için Mastersizer 3000 partikül boyut ölçüm cihazı kullanılmıştır. Lazer difraksiyon tekniğine sahip olan cihaz farklı özelliklere sahip partiküllerin yüzde ve kümülatif olarak boyut dağılımını ölçmektedir. Cihazda ışın saçılımı ile birlikte optik parametreler yardımıyla partiküllerin boyut dağılımları ölçülmüştür. Oda sıcaklığında ve saf su eşliğinde gerçekleştirilen partikül boyut dağılımı analizi sonuçların verimli olması açısından 3'er kez tekrar edilerek nihai sonuçlara ulaşılmıştır. Testler sonucunda, MSZ tozlarının ortalama boyut dağılımı yaklaşık olarak 39,4 $\mu \mathrm{m}$ ölçülürken, CSZ tozlarının ortalama boyut dağılımı yaklaşık olarak 53,3 $\mu \mathrm{m}$ olarak ölçülmüştür. Analizler sonucunda elde edilen \% hacim ve \% kümülatif hacim dağılımı MSZ için Şekil. 2a'da, CSZ için Şekil 2b’de verilmiştir. 


\begin{tabular}{|c|c|c|}
\hline & $\begin{array}{l}\text { BŞEÜ Fen Bilimleri Dergisi } \\
8(2), 604-613,2021\end{array}$ & $\begin{array}{r}\text { BSEU Journal of Science } \\
\text { https://doi.org/10.35193/bseufbd.909078 }\end{array}$ \\
\hline |ER R & & 2458-7575 (https://dergipark.org.tr/tr/pub/bseufbd) \\
\hline
\end{tabular}
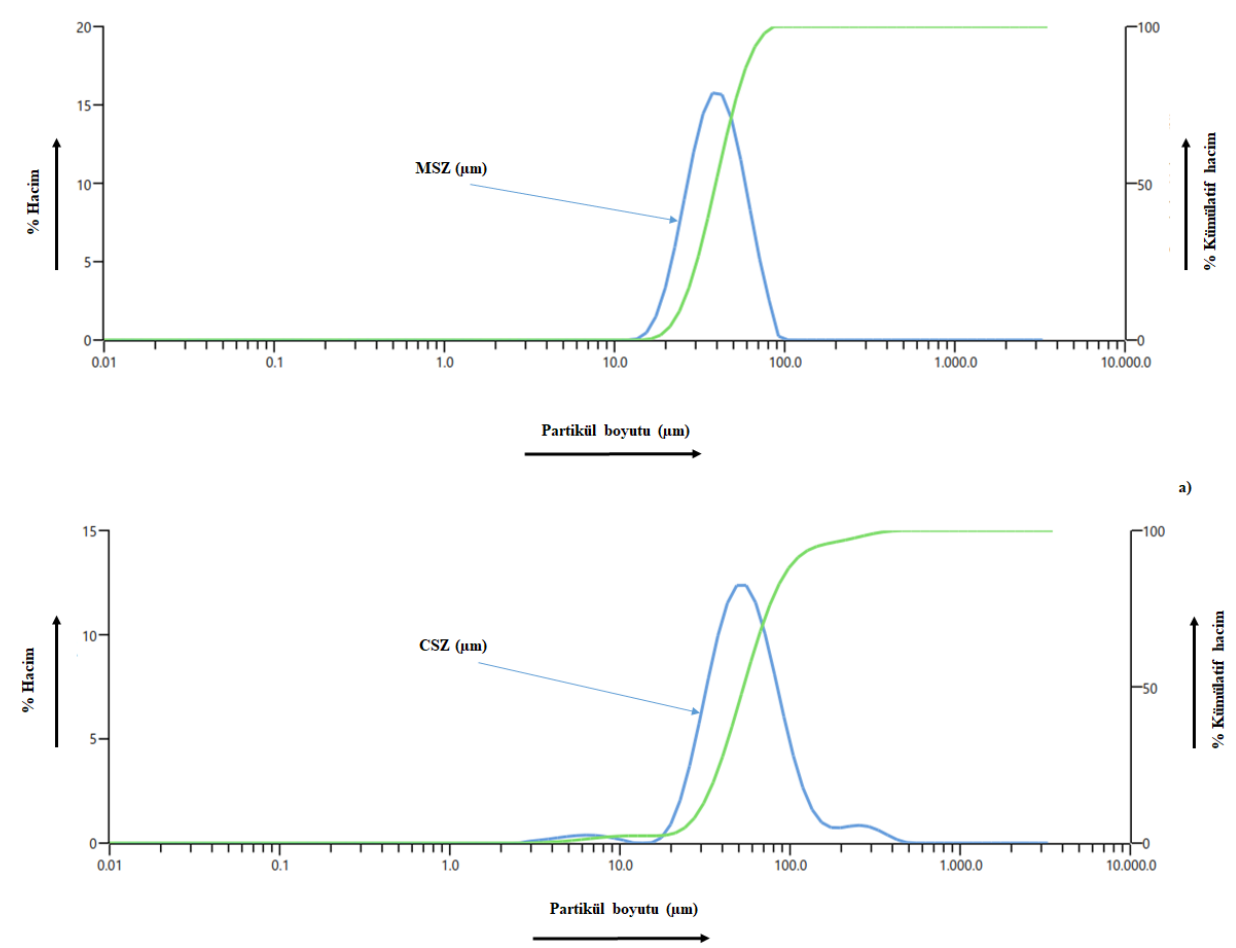

Şekil 2. Kaplama tozlarının partikül boyut dağılımı analizi sonuçları a) MSZ, b) CSZ

MSZ ve CSZ kaplama tozlarının içeriğindeki elementel oranları belirlemek için gerçekleştirilmiş olan noktasal EDS analizinin sonuçları sırasıyla Şekil 3-a ve Şekil 3-b' de verilmiştir. Elde edilen analiz sonuçlarına göre MSZ tozlarının içeriğindeki Mg miktarının \%4,7 ile \%11,2 oranında değişiklik gösterdiği görülmüștür. CSZ içeriğindeki Ca miktarının ise, \%3,2 ile \%4,7 oranında değiştiği gözlemlenmiştir. Elde edilen bu oranlar $\mathrm{ZrO}_{2}$ 'yi stabilize etmek için kullanılmış olan $\mathrm{Mg}$ ve Ca yüzdeleri vermektedir.
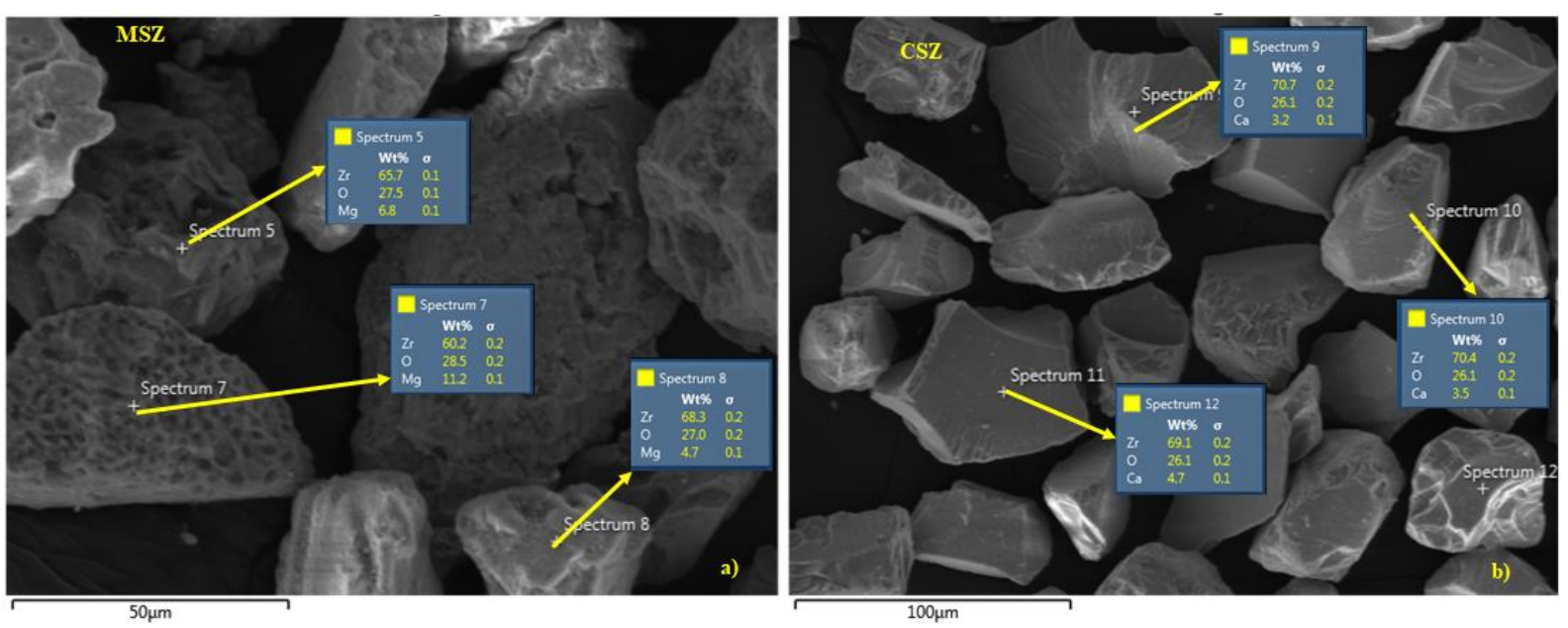

Şekil 3. Kaplamatozlarınınnoktasal EDS analizi a) MSZ, b) CSZ

Saf zirkonya kübik (c), monoklinik ve tetragonal (t) faz yapılarına sahiptir. Zirkonya malzemesinin hangi polimorflara sahip olduğu basınca ve sıcaklığa bağlıdır. Atmosfer basıncı altında $1170^{\circ} \mathrm{C}$ ' ye kadar zirkonya yapısı monoklinik fazda kararlıdır. Atmosfer basıncının sabit kaldığ 1 ve sıcaklığın değiştiği durumlarda $1170^{\circ} \mathrm{C}^{\prime}$ nin üzerinde zirkonya malzemesi polimorfik dönüşüm göstererek $2300^{\circ} \mathrm{C}^{\prime}$ ye kadar tetragonal faz yapısına sahip olur. $2300^{\circ} \mathrm{C}-2700^{\circ} \mathrm{C}$ ye kadar ise, kübik faz yapısında bulunur ve bu sıcaklığın üzerinde ise, ergimeye başlar. Bu üç polimorfik dönüşümün dişında yüksek sıcaklık ve basınçta ortorombik faz yapısı da oluşmaktadır. $\mathrm{Bu}$ faz 
dönüşümleri zirkonya malzemesinde hacimsel değişimler meydana getirmektedir. Bu hacimsel değişiklikler özellikle kaplama malzemesi olarak kullanıldıkları durumlarda termal şok özelliklerinde olumsuz etkiler oluşturur. Olumsuz etkilerin ortadan kaldırılması amaciyla saf zirkonya malzemesine stabilize edici $\mathrm{MgO}$ ve $\mathrm{CaO}$ gibi oksitler ilave edilmektedir [17].Stabilizatör oksitler saf zirkonyayı oda sıcaklığından ergime noktasına kadar kübik kafes yapısında stabil hale getirmektedir. $\mathrm{Bu}$ işlemle birlikte tetragonalden monokliniğe dönüşüm esnasında hacimsel değişikliğin neden olduğu etkiler azaltılmış olmaktadır. Kısmi stabilize zirkonya da ise, iki veya daha fazla faz yapısı bulunabilir. Genellikle ise, kübik ve tetragonal faz yapısı bir aradadır. Kısmi stabize zirkonya da soğuma esnasında tetragonal faz monoklinik faza dönüşebilmektedir. TBC sistemlerinin üretimlerinde kullanılan seramik tozları faz yapılarının belirlenebilmesi için XRD analizine tabi tutulmuştur. Rigaku marka analiz cihazıyla test edilen MSZ ve CSZ seramik tozlarının faz yapıları Şekil 4'te verilmiştir. Gerçekleştirilen XRD analizleri neticesinde üst kaplamada kullanılan MSZ ve CSZ tozlarının kübik, tetragonal ve monoklinik faz yapısını bir arada bulundurduğu görülmektedir.

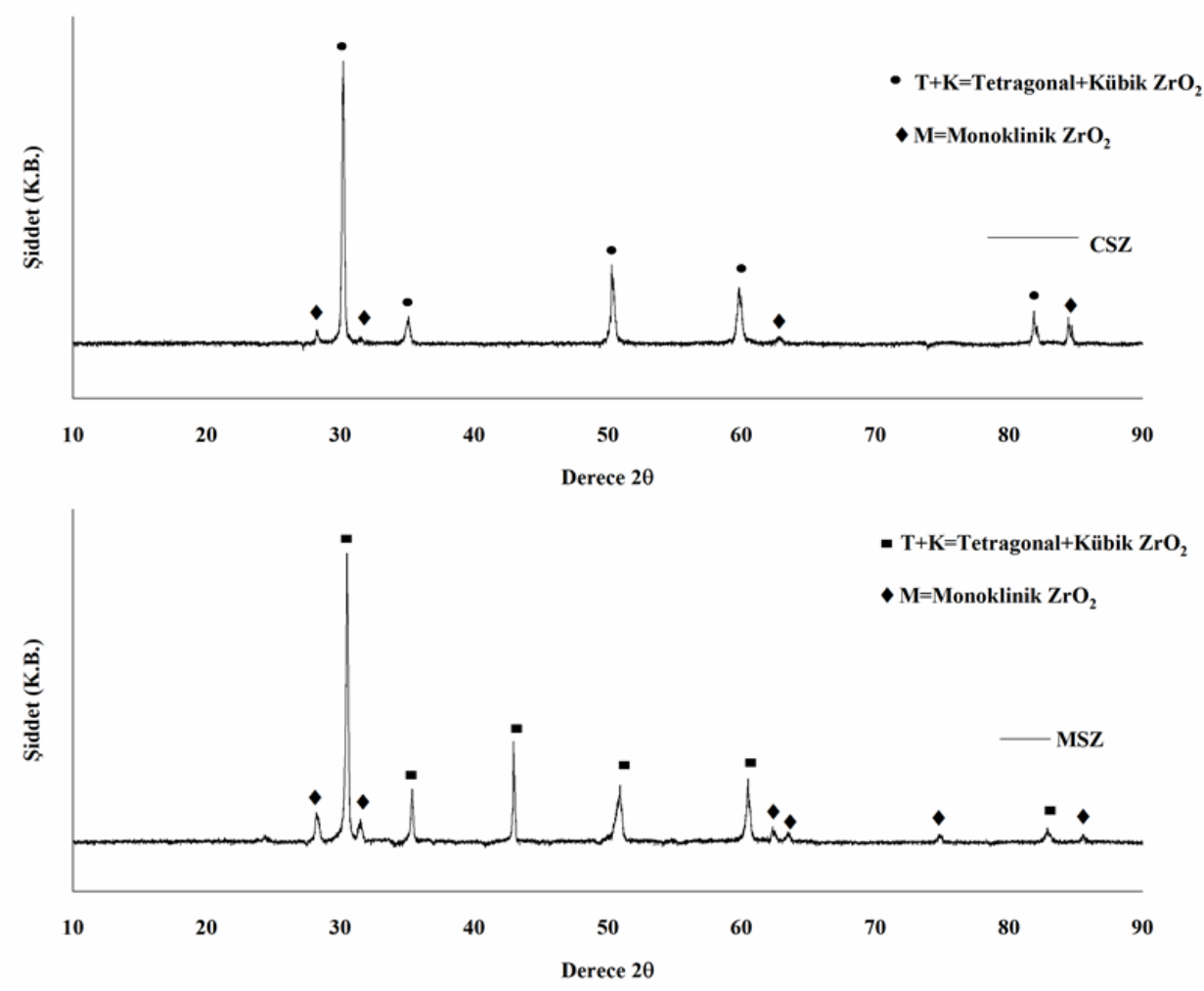

Şekil 4. MSZ ve CSZ tozlarına ait XRD analizi sonuçları

\section{DENEYSEL SONUÇLAR}

Üretilen TBC sistemlerinin mikroyapısal, porozite, sertlik ve yüzey pürüzlülük ölçümleri gerçekleştirilmiştir. Porozite ölçümleri, matris ve gözeneklilik farklılıkların belirlenmesi yoluyla Image J yazılım programı kullanılarak yapılmıştır. 1000x büyütmede kaplamaların farklı bölgelerinden görüntüler alınarak ortalama porozite değerleri belirlenmiştir.

Yüzey pürüzlülüğü ölçümleri için DIN EN ISO 3274 standartlarına uygun SJ-310 Mitutoyo (Japonya) test cihazı kullanılmıştır. Yüzey pürüzlülük değerlerinin belirlenmesi içinde her bir numunenin üst yüzeyinin farklı bölgesinden ölçümler alınarak ortalama pürüzlülük değerleri belirlenmiştir.

Kaplamaların sertlik değerlerinin belirlenmesinde, kaplama yüzeyinden beş farklı derinlikte ölçümler yapılmıştır. Qness, Q10A, Avusturya markalı Duraminmikrosertlik cihazı kullanarak ölçümler gerçekleştirilmiştir. Sertlik ölçümleri, metalik bağ ve seramik kaplamalar için 15 saniyelik bir süre boyunca 100 gramlık yük uygulanarak belirlenmiştir. Her test on kez tekrarlanarak her bir katmanın ortalama sertlik değerleri belirlenmiştir. Üretilen TBC'lerin ortalama porozite yüzdeleri, yüzey pürüzlülüğü ve sertlik değerleri Tablo 4'te verilmiştir. 


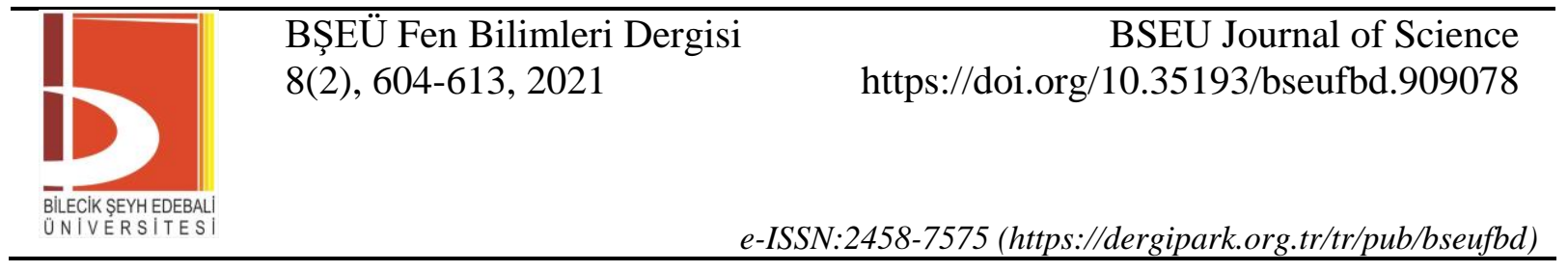

Tablo 4. Kaplamaların porozite, yüzey pürüzlülüğü ve sertliği

\begin{tabular}{cccc}
\hline TBC & Porozite & Yüzey Pürüzlülüğ̈̈ & Sertlik Değeri \\
& $(\boldsymbol{\%})$ & $\left(\mathbf{R}_{\mathbf{a}}, \boldsymbol{\mu} \mathbf{m}\right)$ & $(\mathbf{H v})$ \\
\hline MSZ & $5,15 \pm 1,20$ & $5,75 \pm 0,50$ & $620 \pm 30$ \\
CSZ & $6,25 \pm 1,40$ & $5,80 \pm 0,35$ & $590 \pm 50$ \\
\hline
\end{tabular}

Tablo 4'e göre TBC'lerin bazı fiziksel özellikleri birbirleriyle karşılaştırılabilir. MSZ üst kaplamanın gözeneklilik seviyesi CSZ'nin kinden daha düşüktür, bu da oksijenin bağ tabakası üzerinden difüzyonu için çok önemlidir. TBC'lerin yüzey pürüzlülük değerleri birbirine yakındır. MSZ TBC'nin sertliği, CSZ TBC' nin kinden daha yüksektir, ancak CSZ kaplama daha düşük bir gözeneklilik sergiler. Her iki kaplamaya ait kesitsel SEM görüntüsü Şekil 5.'de verilmiştir. Şekil 5.a'da MSZ kaplamaya ait SEM görüntüsü, Şekil 5.b'de CSZ kaplamaya ait SEM görüntüsü mevcuttur. Bağ kaplama ile MSZ ve CSZ arasında yapısal farklılıklar gözlemlenebilir. Şekilde görüldüğü gibi metalik kaplama yoğun ve gözeneksiz bir yapıya sahiptir. CoNiCrAlY bağ kaplaması üst kaplamalar arasında belirgin bir arayüzey mevcuttur. Her iki seramik üst kaplama tabakası, gözeneklilik ve homojenlik açısından benzer yapılar sergilemektedir.
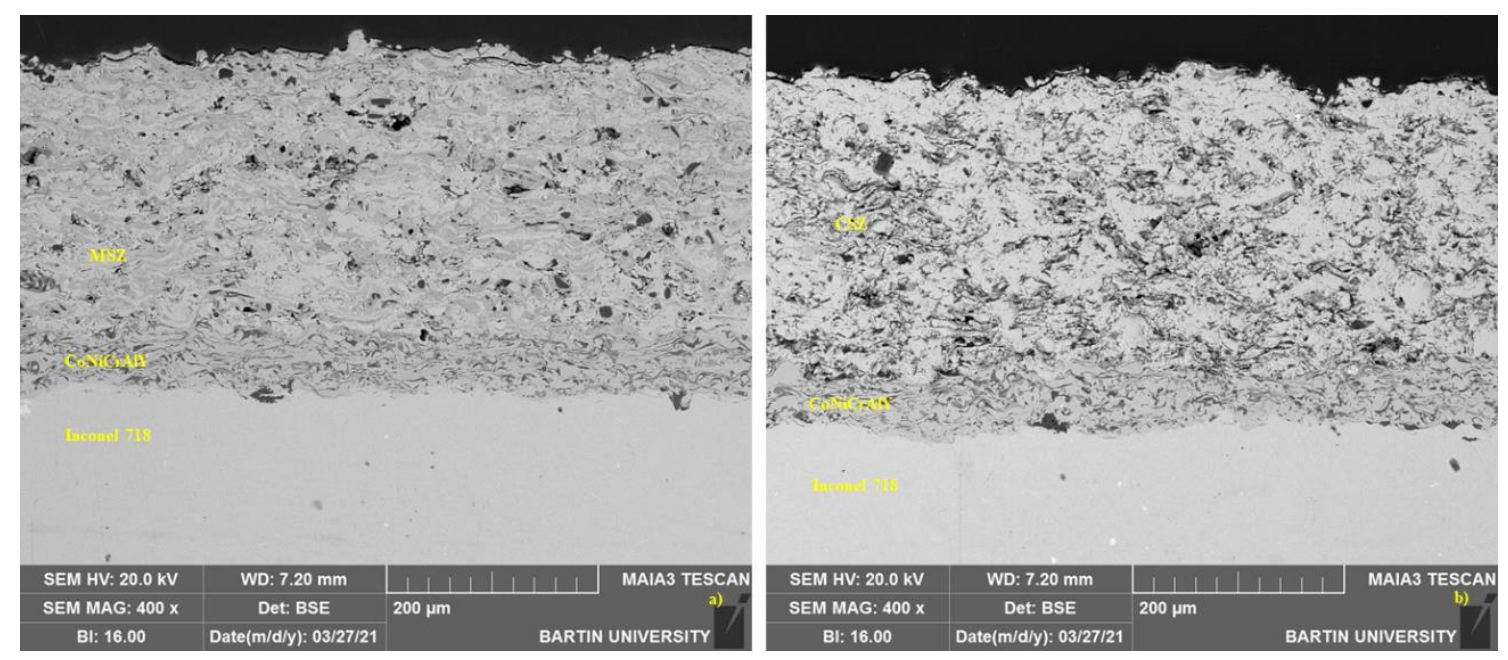

Şekil 5. TBC sistemlerine ait arayüzey SEM görüntüleri a) MSZ kaplama, b) CSZ kaplama

Şekil 6' da APS yöntemiyle bağ kaplaması üretilmiş ve MSZ üst seramik kaplamaya sahip TBC sisteminden elde edilmiş elementel haritalama analizi mevcuttur. Üst kaplama ve bağ kaplama ara yüzeyinden gerçekleştirilmiş olan elementel dağılımda üst kaplama yapısı içerisinde $\mathrm{Mg}, \mathrm{Zr}$ ve O elementlerine yoğun bir şekilde rastlanılmıştır. Üst kısımda birbiri üzerinde bu elementelerin çakışması kaplama içeriğinin MSZ olduğu kanıtlamaktadır. Bağ kaplamada ise, $\mathrm{Co}, \mathrm{Ni}, \mathrm{Cr}$ ve $\mathrm{Al}$ elementlerine yoğun bir şekilde rastlanmıştır. Bağ kaplama içerisinde bu elementlerin varlığ kaplama içeriğinin CoNiCrAlY içeriği olduğunun bir göstergesidir. Y elementinin ise, kaplama oranı içerisindeki yüzdesinin az olmasından dolayı analizde net bir şekilde görülememiştir. Ayrıca hem üst kaplamda hem de bağ kaplamada APS yönteminin karakteristik özelliği olan lamel mikroyapı görülmektedir [1,18-20]. Inconel 718 süper alaşım altlık tabakada da Ni, Fe ve Co elementlerine yoğun bir şekilde rastlanırken Ti elementinin de az da olsa altlık içerisinde bulunduğu görülmektedir. Şekilde siyaha yakın koyu renkli kısımların ise, Al elementi olduğu anlaşılmıştır. 


\begin{tabular}{|c|c|c|}
\hline & $\begin{array}{l}\text { BŞEÜ Fen Bilimleri Dergisi } \\
8(2), 604-613,2021\end{array}$ & $\begin{array}{r}\text { BSEU Journal of Science } \\
\text { https://doi.org/10.35193/bseufbd.909078 }\end{array}$ \\
\hline $\begin{array}{l}\text { CIKSEYHEDEBAL| } \\
\text { IVERSITES| }\end{array}$ & & 2458-7575 (https://dergipark.org.tr/tr/pub/bseufbd) \\
\hline
\end{tabular}

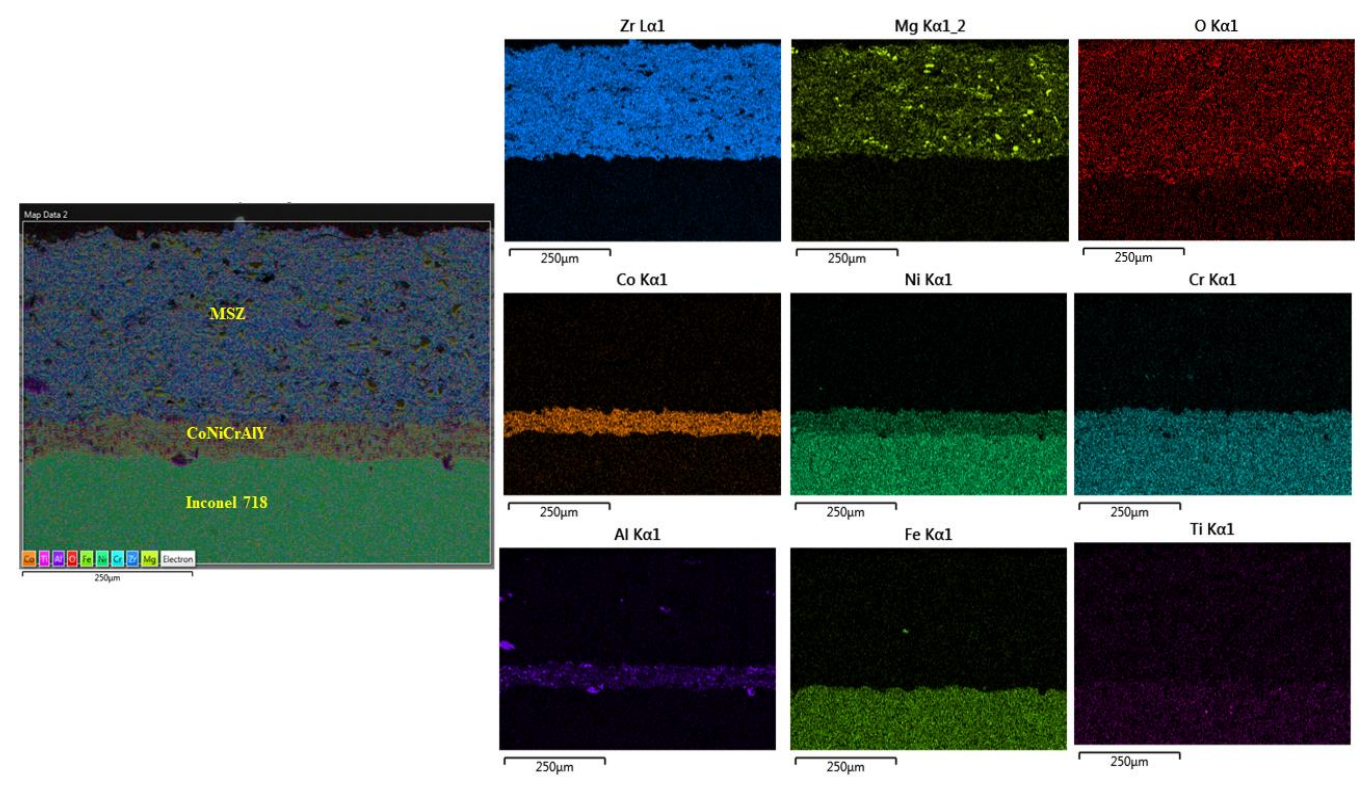

Şekil 6. MSZ TBC sistemine ait SEM mikroyapısal haritalama görüntüsü

Şekil 7' de CSZ üst kaplamaya sahip, CoNiCrAIY metalik bağ kaplamalı TBC sistemine ait elementel haritalama analizinin sonucu verilmiştir. Şekilde hem üst kaplamanın hem de bağ kaplamanın APS yöntemiyle kaplandığı görülmektedir. Üst kaplama tabakasında $\mathrm{Zr}$, Ca ve $\mathrm{O}$ elementlerinin yoğunlukta olduğu ve birbiri üzerinde çakıştığı görülmektedir. Bağ kaplama tabakasında ise, $\mathrm{Co}, \mathrm{Ni}, \mathrm{Cr}$ ve $\mathrm{Al}$ elementlerinin yoğunluğu görülmektedir. Analiz sonuçlarından Inconel 718 ve bağ kaplama ara yüzeyinde bazı bölgelerde koyu renkli bölgenin de alüminyumca zengin olduğu anlaşılmıştır. Inconel 718 süper alaşım altlık tabakada da $\mathrm{Ni}, \mathrm{Cr}$ ve $\mathrm{Fe}$ elementlerince yoğun olduğu ve eser miktarda Ti elementinin olduğu anlaşılmıştır.

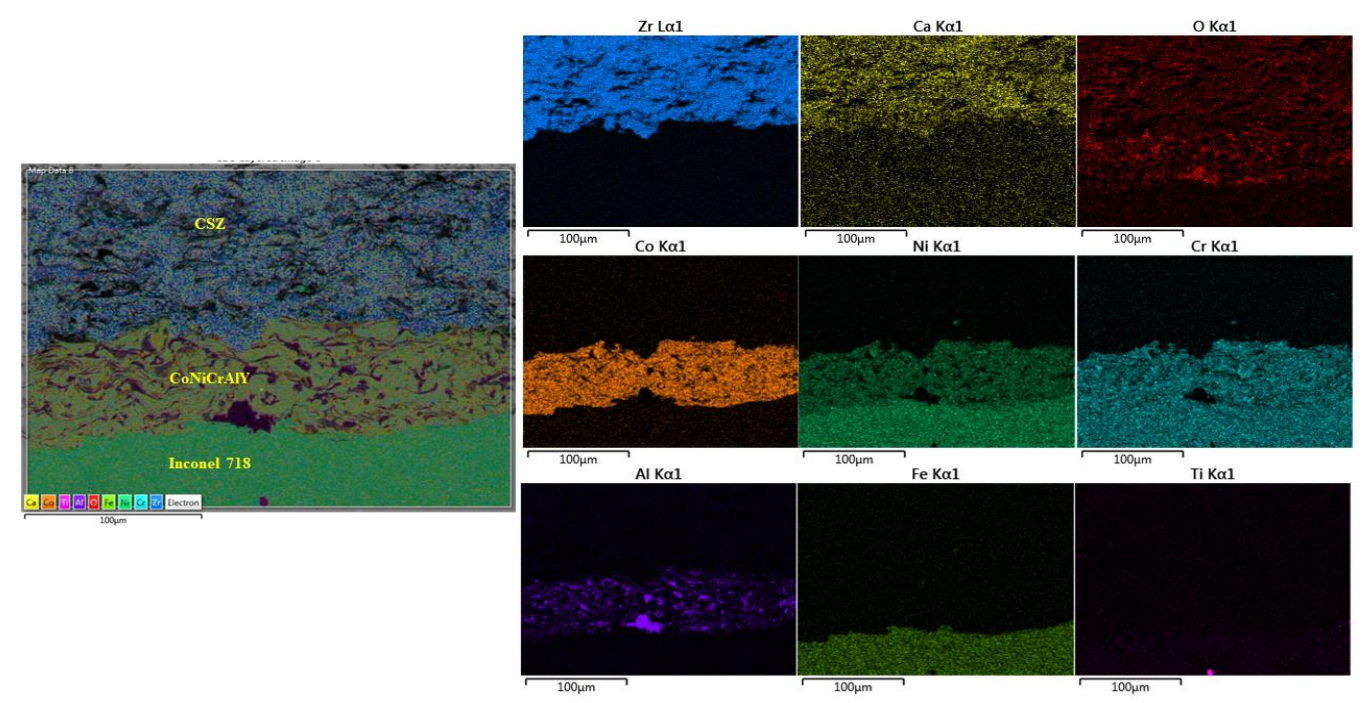

Şekil 7. CSZ TBC sistemine ait SEM mikroyapısal haritalama görüntüsü

Yapı içerisinde tetragonal, monoklinik ve kübik fazların miktarları ve dağılımları seramik üst kaplama malzemesi olan zirkonyanın karakteristik özelliklerinde oldukça etkilidir. Kısmi stabilize zirkonya genellikle iki veya daha fazla fazın birlikte bulunmasıyla yapılır. Kübik faz ve tetragonal faz birlikte bulunabilir ve soğuma sırasında tetragonal fazı monoklinik faza dönüşebilir. Şekil 8' de APS yöntemiyle bağ kaplaması ve üst kaplaması üretilen MSZ ve CSZ TBC sistemlerine ait faz analizi mevcuttur. Kısmi olarak stabilize edilen zirkonya esaslı üst kaplamaların üst yüzeyinden gerçekleştirilen XRD analizlerine göre, TBC sisteminin genel itibariyle tetragonal, kübik ve çok az miktarda monoklinik faz yapısında stabilitesi sağlanmış durumda olduğu görülmektedir. Kısmi 
olarak stabilitesi sağlanmış olan kaplamaların ani sıcaklık değişimlerinde faz kararlılığını koruyacağı ve faz değişiminden kaynaklanan hacim artışlarının önüne geçileceği düşünülmektedir. Kısmi stabilize zirkonya malzemesinin termal genleşmesinin saf zirkonyadan ve tamamen stabilize zirkonyadan daha düşük olması, tamamen stabilize ve monoklinik zirkonya fazından daha iyi bir termal şok direnci olduğu göstermektedir [7, 17].
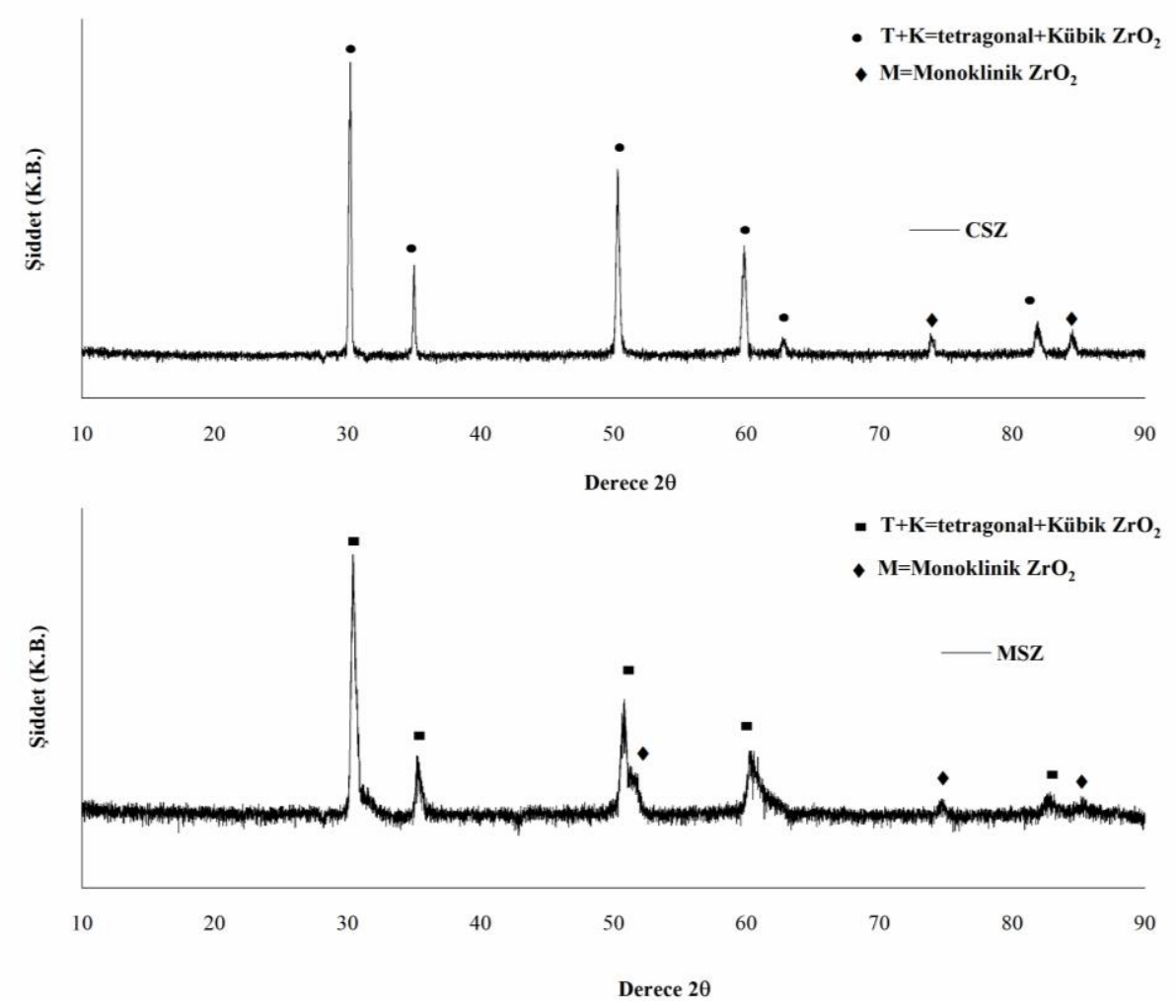

Şekil 8. Üretilen MSZ ve CSZ TBC sistemlerine ait XRD analiz sonuçları

\section{SONUÇLAR}

Inconel 718 süper alaşım altlık malzeme üzerine CoNiCrAlY metalik bağ, MSZ ve CSZ içerikli TBC sistemlerinin üretimleri başarılı bir şekilde gerçekleştirilmiştir. Geleneksel olarak kullanımda olan YSZ TBC sistemine göre alternatif stabilize olan MSZ ve CSZ malzemelerinin özelliklerinin görülebilmesi amaciyla gerçekleştirilen çalışmada, kaplama sistemlerinin mikroyapısal olarak porozite, oksit ve genel olarak kaplama yüzey yapıları değerlendirilmiş mekaniksel özelliklerin incelenmesinde ise sertlik ve yüzey pürüzlülük ölçüm sonuçları değerlendirilmiştir. APS tekniği kullanılarak üretilen metalik ve seramik esaslı kaplama yapılarında özellikle seramik üst kaplama yapılarının oksit ve porozite içeriğine sahip olduğu bu durumun üretim yöntemi esaslı kaynaklanan APS sistemin tipik karakteristik özelliğinin bir sonu olarak oluştuğu görülmüştür. MSZ TBC sisteminin daha üniform mikroyapısal özelliğe ve buna bağlı daha az oksit ve porozite içeriğine sahip olduğu görülmüştür. Her iki TBC sistemi için de gerçekleştirilen XRD analizleri neticesinde faz sabitleyici olarak kullanılan içerikler ve tetragonal $\mathrm{ZrO}_{2}$ yapısı görülmüştür. Yapılan çalışmalar neticesinde her iki TBC sistemininde birbirine benzer özellikler taşıdığı belirlenmiştir. İlerleyen çalışmalarda üretilen MSZ ve CSZ TBC sistemlerinin yüksek sıcaklık izotermal oksidasyon ve termal çevrim davranışlarının incelenerek kaplama sistemlerinin servis koşulları altındaki kullanımda sergileyecekleri dayanım performanslarının belirlenmesi planlanmıştır.

\section{TEŞEKKÜR}

Deneysel çalışmaların gerçekleştirilmesinde faydalanılan makine, ekipman, teçhizat ve analizler yönüyle Bartın Üniversitesi, Merkezi Araştırma Laboratuvarı Uygulama ve Araştırma Merkezine (BUMLAB) teşekkür ederim. 


\section{KAYNAKLAR}

[1] Doleker, K. M., Ozgurluk, Y., \& Karaoglanli, A. C. (2018). Isothermal oxidation and thermal cyclic behaviors of YSZ and double-layered $\mathrm{YSZ} / \mathrm{La}_{2} \mathrm{Zr}_{2} \mathrm{O}_{7}$ thermal barrier coatings (TBCs). Surf. Coatings Technol, 351, 78-88.

[2] Padture, N., Schlichting, K., Bhatia, T., Ozturk, A.,Cetegen, B., Jordan, E., Gell, M., Jiang, S., Xiao, T., Strutt, P., et al. (2001).Towards durable thermal barrier coatings with novel microstructures deposited by solution-precursor plasma spray. Acta Mater., 49, 2251-2257.

[3] Stiger, M. J., Yanar, N. M., Topping, M. G., Pettit, F. S., \& Meier, G. H. (1999). Thermal barrier coatings for the 21st century. Zeitschrift Fur Met.

[4] Keyvani, A., Bahamirian, M., \& Kobayashi, A. (2017). Effect of sintering rate on the porous microstructural, mechanical and thermomechanical properties of YSZ and CSZ TBC coatings undergoing thermal cycling. $J$. Alloys Compd., 727, 1057-1066.

[5] Cao, X. Q., Vassen, R., \& Stoever, D. (2004). Ceramic materials for thermal barrier coatings. J. Eur. Ceram. Soc., 24, 1-10.

[6] Ozgurluk, Y., Doleker, K. M., Ahlatci, H., Ozkan, D., \& Karaoglanli, A. C. (2018). The microstructural investigation of vermiculite-infiltrated electron beam physical vapor deposition thermal barrier coatings. Open Chem., 16, 1106-1110.

[7] Doleker, K. M., Ozgurluk, Y., Ozkan, D., Mesekiran, N., \& Karaoglanli, A. C. (2018). Comparison of microstructures and oxidation behaviors of Ytria and magnesia stabilized zirconia thermal barrier coatings (TBC). Mater. Tehnol., 52, 315-322.

[8] Qi, H.Y., \& Yang, X.G. (2012). Computational analysis for understanding the failure mechanism of APSTBC. Comput. Mater. Sci., 57, 38-42.

[9] Ma, W., Gong, S., Xu, H., \& Cao, X. (2006). The thermal cycling behavior of Lanthanum-Cerium Oxide thermal barrier coating prepared by EB-PVD. Surf. Coatings Technol., 200, 5113-5118.

[10] Vaßen, R., Traeger, F., \& Stöver, D. (2004). New Thermal Barrier Coatings Based on Pyrochlore/YSZ Double-Layer Systems. Int. J. Appl. Ceram. Technol., 1, 351-361.

[11] Choi, S. R., Bansal, N. P., \& Zhu, D. (2005). Advances in Ceramic Coatings and Ceramic-Metal Systems Advances in Ceramic Coatings and Ceramic-Metal Systems. In; Zhu, Dongming; Plucknett, K., Ed., The American Ceramic Society, Ohio, 11-19.

[12] Ozgurluk, Y., Doleker, K. M., Ozkan, D., Ahlatci, H., \& Karaoglanli, A. C. (2019). Cyclic hot corrosion failure behaviors of EB-PVD TBC systems in the presence of sulfate and vanadate molten salts. Coatings, 9 , 166.

[13] Strangman, T., Raybould, D., Jameel, A., \& Baker, W. (2007). Damage mechanisms, life prediction, and development of EB-PVD thermal barrier coatings for turbine air foils. Surf. Coatings Technol.

[14] Eliaz, N., Shemesh, G., \& Latanision, R. M. (2002). Hot corrosion in gas turbine components. Eng. Fail. Anal., 9, 31-43.

[15] Özgürlük, Y. (2016). Soğuk Gaz Dinamik Sprey (CGDS) Kaplama Yöntemiyle Üretilen Termal Bariyer Kaplamaların (TBC) Sicak Korozyon Davranışlarının İncelenmesi. Yüksek Lisans Tezi, Bartın Üniversitesi, Fen Bilimleri Enstitüsü, Bartın.

[16] Karaoğlanlı, A. C. (2012). Termal Bariyer Kaplamalarda Bă̆ Tabakasının Farklı Yöntemlerle Üretilmesi ve Özelliklere Etkisi. Doktora Tezi, Sakarya Üniversitesi, Fen Bilimleri Enstitüsü, Sakarya.

[17] Köroğlu, V. (2013). Refrakter Üretimine Yönelik Olarak Zirkonya Stabilizasyon Çalışmaları Doktora Tezi, İstanbul Teknik Üniversitesi, Fen Bilimleri Enstitüsü, İstanbul.

[18] Wei, Z. Y., \& Cai, H. N. (2019). Stress states and crack behavior in plasma sprayed TBCs based on a novel lamellar structure model with real interface morphology. Ceramics International, 45(14), 16948-16962.

[19] Cheng, B., Yang, N., Zhang, Q., Zhang, Y. M., Chen, L., Yang, G. J., \& Li, C. J. (2017). Sintering induced the failure behavior of dense vertically crack and lamellar structured TBCs with equivalent thermal insulation performance. Ceramics International, 43(17), 15459-15465.

[20] Wei, Z. Y., Cai, H. N., Meng, G. H., Tahir, A., \& Zhang, W. W. (2020). An innovative model coupling TGO growth and crack propagation for the failure assessment of lamellar structured thermal barrier coatings. Ceramics International, 46(2), 1532-1544. 